\title{
Hydrogen Gas Production in a Stand-Alone Wind Farm
}

\author{
Mohammad Naziry Kordkandy \\ National Iranian Gas Transmission \\ Company-8th District of Gas \\ Transmission Operation (NIGTC- \\ DIST8), Tabriz, Iran \\ m_naziri@nigc-dist8.ir
}

\author{
Ardeshir Arash \\ Department of Electrical \\ Engineering, Ardabil Branch, \\ Islamic Azad University, Ardabil \\ Iran \\ ardeshir.arash@gmail.com
}

\author{
Mohsen Nazary Kordkandy \\ Faculty of Electrical \& Computer \\ Engineering, University of \\ Mohaghegh Ardabili, Ardabil \\ Iran \\ mohsennazari90@gmail.com
}

\begin{abstract}
This paper is analyzing the operation of a stand-alone wind farm with variable speed turbines, permanent magnet synchronous generators (PMSG) and a system for converting wind energy during wind speed variations. On this paper, the design and modeling of a wind system which uses PMSG's to provide the required power of a hydrogen gas electrolyzer system, is discussed. This wind farm consists of three wind turbines, boost DC-DC converters, diode full bridge rectifiers, permanent magnet synchronous generators, MPPT control and a hydrogen gas electrolyzer system. The MPPT controller based on fuzzy logic is designed to adjust the duty ratio of the boost DCDC converters to absorb maximum power. The proposed fuzzy logic controller assimilates, with (PSF) MPPT algorithm which generally used to absorb maximum power from paralleled wind turbines and stores it in form of hydrogen gas. The system is modeled and its behavior is studied using the MATLAB software.
\end{abstract} MPPT.

Keywords-Wind turbine; Fuzzy logic; hydrogen; PMSG;

\section{INTRODUCTION}

Wind energy conversion systems (WECSs), the interest is focused on small units, used to provide electricity supply in remote areas that are beyond the reach of an electric power grid or cannot be economically connected to a grid [1-2]. However, in order to use wind power as an independent power supply, it is necessary to equalize the change in the amount of power generated, due to the intermittent nature of wind. One such possible method is to use the wind power to produce hydrogen, Hydrogen has attracted attention as a future source and it is an effective means of energy storage [3]. In case of grid-connected wind farms, the frequency fluctuations in the connected power grid due to wind power variations are also to be considered, as well as grid proximity [4]. Various topologies have been proposed for hydrogen production in which the hydrogen electrolyzer is connected to dc link frequency converter and a battery is generally used [5]. Using a battery has the disadvantages of losses and low energy density batteries. Thus, a hydrogen is used $[6,7]$.

In this paper we propose a WECS that has multiinput/multi-output DC/DC boost converters [8] with a hydrogen production system shared between converters. In this system we connect three variable speed wind turbines, three permanent magnet synchronous generators (PMSG), three boost converters and a Hydrogen electrolyzer. The hydrogen production system is composed of multiple wind generators. Thus, multiple generators supply the total power to the hydrogen generator, and thus a smoothing effect can be obtained. Therefore, this system can be operated without a battery [4].

Schemes with multiple wind generators connected in parallel through power converters have been proposed with the generators output voltage delivered through a power converter to the load [9]. a ,In this approach however multi input DC/DC converter is employed. The paralleling of switching converters based on power supply contributes many advantages when compared with a single high power centralized power supply [10]. The connection of multi-input/multi-output DC-DC converters in parallel, with the load shared between modules reduces the current stress on the switching devices and increases system reliability [11]. For the reason that conventional PI controller generally does not work well for nonlinear systems, high-order systems and complex systems that have no precise mathematical models, fuzzy logic is chosen to overcome these difficulties due to its flexibility and facility to apply in real time control. With this proposed method, wind generator gives maximum power without any knowledge about generator's characteristic or ambient condition. Control algorithm is independent, achieving fast dynamic responses for the complex nonlinear system $[12,13]$.

\section{THE PROPOSED WIND CONVERSION SYSTEM}

In designing the wind conversion system for the current study, a few points below will be considered. First, as in variable wind conversion system speed varies due to fluctuations in wind speed, voltage, power and frequency of the output, thus, the most important aspect of designing a wind system are considered using an appropriate algorithm for obtaining the highest power possible from a wind turbine. In this study, we will use PSF algorithm along with intelligent fuzzy controller. In order to have the optimum use of the area 
potential for the installation of wind systems, some wind turbines are used in a combined manner. The advantages of this method include increasing the reliability of turbines operation, obtaining a total capacity of turbines and applying them to the hydrogen storage system. In this study, we have considered the use of hydrogen electrolysis system for hydrogen production in the output of wind systems. It should also be noted that a combination of low-capacity hydrogen electrolysis systems is used instead of a high-capacity electrolysis system. Regarding the fact that measuring the wind speed is difficult and costly, the Maximum Power Point Tracking (MPPT) function is generally computed without measuring the wind flow velocity by using the generators speed. This is also one of the strengths of this study.

The overall schematic of the proposed wind system is shown in Figure 1. As shown, the proposed system consists of three identical sets of wind turbines, permanent magnet synchronous generators, AC-DC full-wave bridge rectifiers, DC boost converters and a control system.

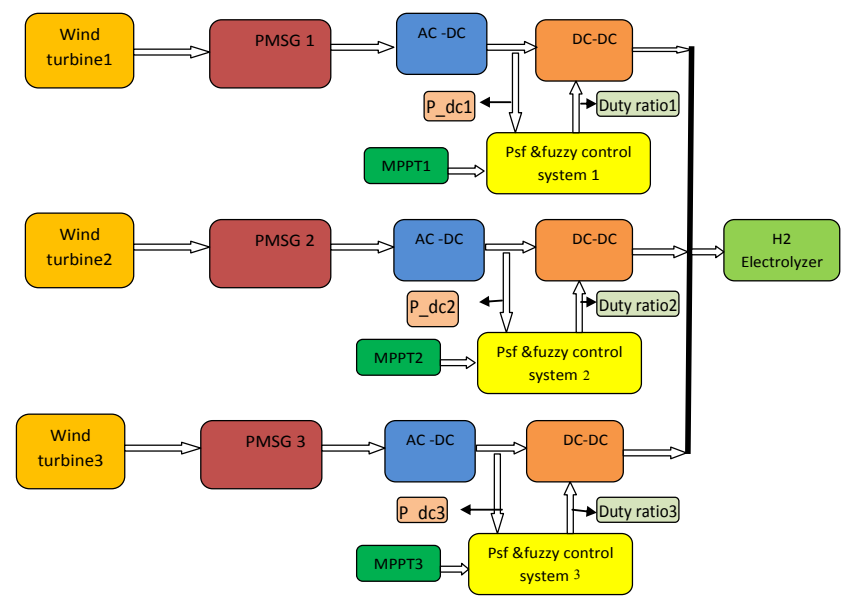

Fig. 1. Wind turbines configuration

The DC power $\left(\mathrm{P}_{\mathrm{dc}}\right)$ generated from each generator is compared with a maximum turbine power (MPPT) in each of the control blocks and this error signal provides a suitable duty ratio for each of the dc-dc boost converters by the fuzzy control systems. Finally, the boost converters totally impose suitable voltages and powers for hydrogen electrolysis system.

\section{A. Wind turbine model}

The turbine power is determined by the power coefficient $\mathrm{Cp}=f(\lambda, \beta)$ where $\lambda$ is the tip speed ratio and the pitch angle $\beta$ is determined by the shape of the wind turbine blade. Turbine parameters are given in Table I. Wind energy depends on four parameters: volume (the amount of air), velocity (air speed), density (air mass) and flux (air flow through the area). Mechanical power obtained from the wind turbines is defined as follows:

$$
P_{m}=\frac{1}{2} c_{p} \rho A v^{3}
$$

$\mathrm{P}_{\mathrm{m}}$ : Mechanical power in the moving air (watt) $\rho:$ air density $\left(\mathrm{kg} / \mathrm{m}^{3}\right)$

A: area swept of the rotor blades $\left(\mathrm{m}^{2}\right)$

$V$ : velocity of the air $(\mathrm{m} / \mathrm{sc})$

$\mathrm{c}_{\mathrm{p}}$ : The power coefficient

In (1), $c_{p}$ is a function of pitch angle $\beta$ and tip speed ratio $\lambda$. The pitch angle $\beta$ is determined by the shape of the wind turbine blade. The tip speed ratio $\lambda$ is a controllable parameter that is influenced by the wind turbine rotation speed. The tip speed is defined as:

$$
\begin{aligned}
& \lambda=\frac{v_{m}}{v}=\frac{\omega_{m} R}{v} \\
& \omega_{\mathrm{m}}: \text { Rotor angular velocity } \mathrm{rad} / \mathrm{s} \\
& \text { R: Turbine blade radius } \mathrm{m}
\end{aligned}
$$

\section{$\mathrm{V}$ : The average wind velocity $\mathrm{m} / \mathrm{s}$}

Several kind of equations are used to express turbines $c_{p}$ $(\beta, \lambda)$. The following equation is based on the modeling of the wind turbine features and is used for the wind turbine in our study [13]:

$$
\begin{gathered}
c_{p}(\beta, \lambda)=\left(\frac{c_{2}}{\lambda_{i}}-c_{3} \beta c_{5}-c_{6}\right) \exp \left(-\frac{c_{7}}{\lambda_{i}}\right) \\
\frac{1}{\lambda_{i}}=\frac{1}{\lambda+\mathrm{c}_{8} \beta}-\frac{\mathrm{c}_{9}}{\beta^{3}+1}
\end{gathered}
$$

$\mathrm{C}_{1}$ to $\mathrm{C}_{9}$ are $\mathrm{C}_{1}=0.73, \mathrm{C}_{2}=151, \mathrm{C}_{3}=0.58, \mathrm{C}_{4}=0.002, \mathrm{C}_{5}=2.14$, $\mathrm{C}_{6}=13.2, \mathrm{C}_{7}=18.4 \mathrm{C}_{8}=-0.02$ and $\mathrm{C}_{9}=-0.003$. Figure 2 shows the curve of the power factor in $\lambda$ according to different values of $\beta$ for the turbine. It can be observed that firstly the highest power factor is obtained for $\beta=0$. Second, the highest power factor occurs due to a certain amount of tip speed ratio. Therefore, the controller should set $\lambda$ at its optimal value to absorb maximum power in different wind velocities.

To calculate the optimal value of $\lambda$ and the maximum $\mathrm{C}_{\mathrm{p}}$ :

$\frac{d P_{m}}{d \lambda}=0 \rightarrow \frac{d c_{p}}{d \lambda}=0, \quad \beta=0 \rightarrow \lambda o p t=\frac{c_{2}+c_{6} c_{7}+c_{2} c_{9} c_{7}}{c_{2} c_{7}}$

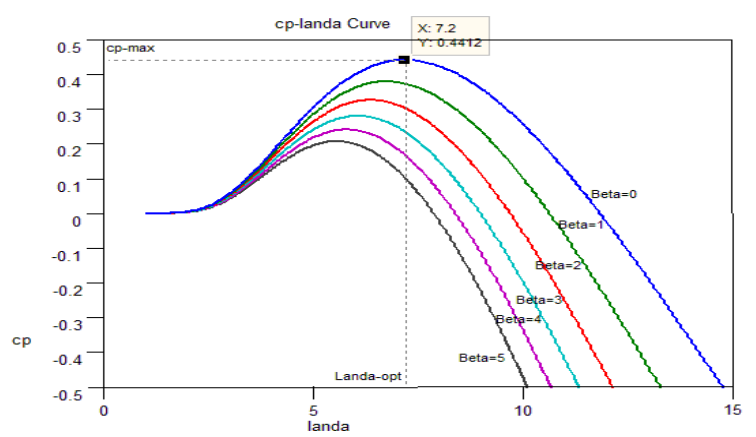

Fig. 2. Cp curves as function of tip-speed-ratio with different pitch angles (the optimum tip speed ratio $\lambda$ opt is 7.2064)

The amount of $c_{p_{\max }}$ is obtained by replacing $\lambda o p t$ in (3):

$$
c_{p_{\max }}=0.4412 .
$$


Replacing $\lambda o p t$ in (2) results in:

$$
\lambda \text { opt }=\frac{\omega_{o p} R}{v} \rightarrow \quad \omega_{o p}=0.2 \mathrm{v}
$$

Using the turbine rotor angular velocity in a range of variable speed wind turbine operation and there will be no need to measure the wind velocity. Given that measuring the wind velocity is difficult and costly, then the MPPT function, without measuring wind velocity, can be generally expressed by the following equation:

$$
P_{M P P T}=0.5 \rho \pi R^{2}\left[\frac{\omega R}{\lambda o p t}\right]^{3} c_{P_{\max }}
$$

Figure 3 shows the characteristic curve of the wind turbine with regard to the turbine power, rotor speed and wind speed. The black line (dashed line) shows the direction of MPPT and the output power of the turbo generator follows this line. In this study, the given wind speed is always lower than the rated wind speed, thus $\beta$ is zero.

\section{B. Hydrogen electrolyzer characteristic}

Technical specifications of the electrolyzer system used in the study are chosen from a technical report as a high-purity hydrogen and oxygen (HHIG) production [14,15]. An electrolyzer cell is an equivalent of an electromotive force $V_{0}$ and internal resistance $R 0$ (Figure 4). During nominal operation, the electrolyzer consumes $44.075 \mathrm{~kW}$ of nominal power. Nominal flow rate of hydrogen is $7.5 \mathrm{Nm} 3 / \mathrm{h}$ when the amount of current and voltage is 410 amps and 107.5 volts, respectively. The hydrogen electrolyzer system used in this study is a combination of modules described in [14] that are 34 rows and two parallel rows.

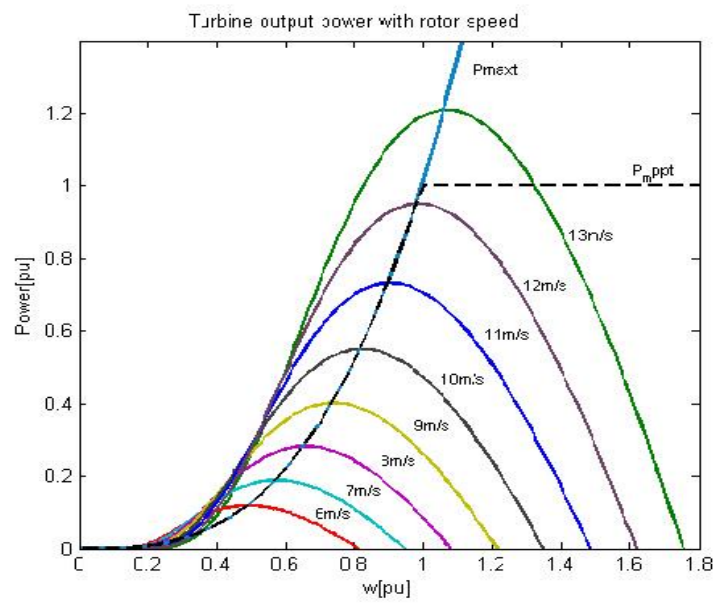

Fig. 3. Wind turbine power characteristics

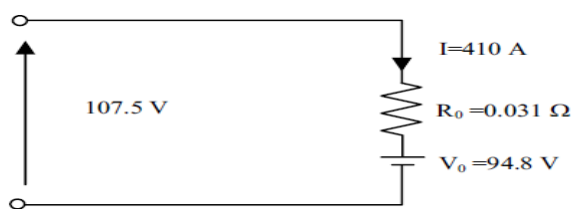

Fig. 4. Equivalent circuit of an electrolyzer cell

\section{THE PROPOSED CONTROL SYSTEM}

In this study, PSF algorithms along with a fuzzy controller are used. In Figure 5, the general principles of this method are shown for a set of wind turbines. Optimum wind energy extraction is achieved by running the wind turbine generator (WTG) in variable-speed variable-frequency mode. The rotor speed is allowed to vary in sympathy with the wind speed by maintaining the tip speed ratio to the value that maximizes aerodynamic efficiency. In order to achieve this ratio, the permanent-magnet synchronous generator (PMSG) load line should be matched very closely to the maximum power line of the wind turbine generator. In such a case, a good matching exists between the generator and the load for the best performance of the system, as well as the maximum utilization of the wind driven PMSG. However, the recent advancements in power electronics and control strategies have made it possible to regulate the voltage of the PMSG in many different ways. Power Signal Feedback controller gets all the inputs from electrical signals in circuit. Wind speed sensor is not necessary for the Power Signal Feedback method. However, it requires an accurate knowledge of WECS to make an estimation. Using turbine rotor angular velocity in a range of variable speed wind turbine operation and there will be no need to measure the wind velocity.

$$
\lambda \mathrm{opt}=\frac{\omega_{o p} R}{v} \rightarrow \quad \omega_{o p}=0.2 \mathrm{v}
$$

And we use $\omega_{o p}$ instead of wind speed for power calculation.

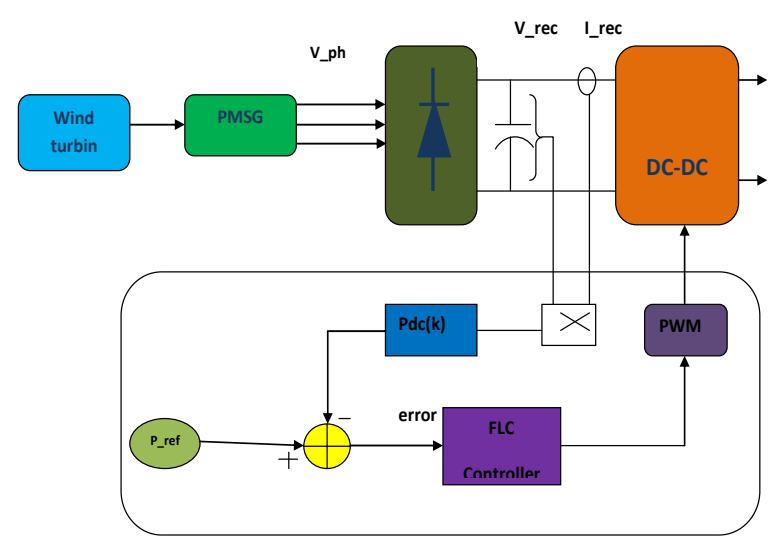

Fig. 5. The proposed system with a Fuzzy Logic Controller and PSF algorithm for a wind turbine

In this control system, $P_{-}$ref, which is the same as $P_{-} M P P T$ is calculated based on (3), whose only variable is $\omega$ (i.e. the permanent magnet synchronous generator speed), for each of the turbo-compressors and is compared with the power generated via the turbo-compressors and the error signal is applied to the fuzzy controller. The output of the fuzzy controller is modulated using a saw-tooth wave and the duty ratio of each boost converter is produced. The proposed MPPT algorithm is based on a fuzzy logic controller that directly adjusts the DC/DC converter duty cycle to the control generator speed. 


\section{A. Fuzzy controller design}

Designing two inputs-one output fuzzy controller of a Mamdani-type includes the following steps: Fuzzification, creating rule-bases, inference, defuzzification. A general schematic of a fuzzy control system with feedback is shown in Figure 6.

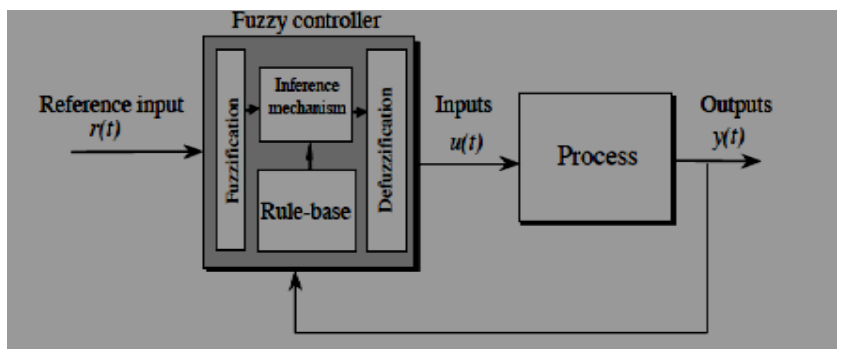

Fig. 6. A schematic diagram of a fuzzy system with feedback.

Designing fuzzy controllers is based on a sufficient knowledge of a system's behaviors instead of on an exact mathematical model [13]. There are two inputs for the fuzzy controllers of the boost converters. The first input is the output error of the system and is shown in (8).

$$
\mathrm{e}(\mathrm{k})=P_{r e f_{i}}-P_{i}(\mathrm{k})
$$

The second input is the difference between consecutive errors and is shown in (9).

$$
\operatorname{de}(\mathrm{k})=e(k)-e(k-1)
$$

Both inputs are fed with the fuzzy controller and the fuzzy controller output is duty ratio changes $\operatorname{Dd}(\mathrm{k})$. Therefore, the control scheme is shown in Figure 7. In this control system, the fuzzy controller output $\operatorname{Dd}(\mathrm{k})$ is added to the previous value of duty ratio and the desired output is finally obtained for the duty ratio.

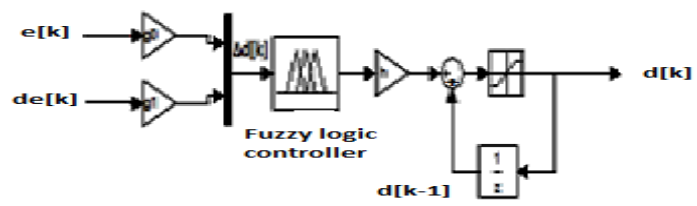

Fig. 7. Block diagram of the FLC

$$
\mathrm{d}(\mathrm{k})=\mathrm{d}(\mathrm{k}-1)+\mathrm{Dd}(\mathrm{k})
$$

In the fuzzification phase, CRISP quantities change to fuzzy. However, before this phase, the scale of the two input signals of error (e) and change error (de) is altered in an appropriate manner using scaling factors,. Then, two scaled signals are fuzzificated to two fuzzy variables called linguistic variables. Fuzzy levels are not fixed and depend on the resolution of the required inputs applications. Bigger fuzzy levels are indicative of high-resolution input. The fuzzy controller uses triangular membership functions in the controller input. The triangular one was chosen due to its simplicity. For an actual data, the fuzzification system finds its fuzzy membership degree in each language variable. In this study, we used a five-level fuzzification system. Each of these variables includes 5 language clauses which shall be called adverbs and respectively include PB (positive big), PS (positive small), ZO (zero), NS (negative small) and NB (negative big). The graphical representation of the categories is as shown in Figure 8. The controller output is the duty ratio of the boost chopper and its membership functions respectively are: NB (negative small), NS (negative small), ZO (zero), PS (positive small) and PB (positive big). The next step is creating rule-bases.

The design of these rules depends on the knowledge and experience of its users. With two inputs and 5 linguistic variables for each input, there will be 25 rules. The rule-base used in this study is in accordance with Table I. In the inference process, the introduction parts of all rules are compared with the inputs to determine the rules appropriate to the current situation. Then, the appropriate rules are chosen and applied.

\section{Simulation AND RESUlts}

The entire control system of the proposed FLC based MPPT algorithm was simulated by MATLAB/SIMULINK. The control system consists of 3 wind turbines model, 3 fuzzy logic controller, 3 PMSG model, 3 DC/DC converter and a Hydrogen production system. Wind turbines and PMSG's model parameters are shown in Table II.

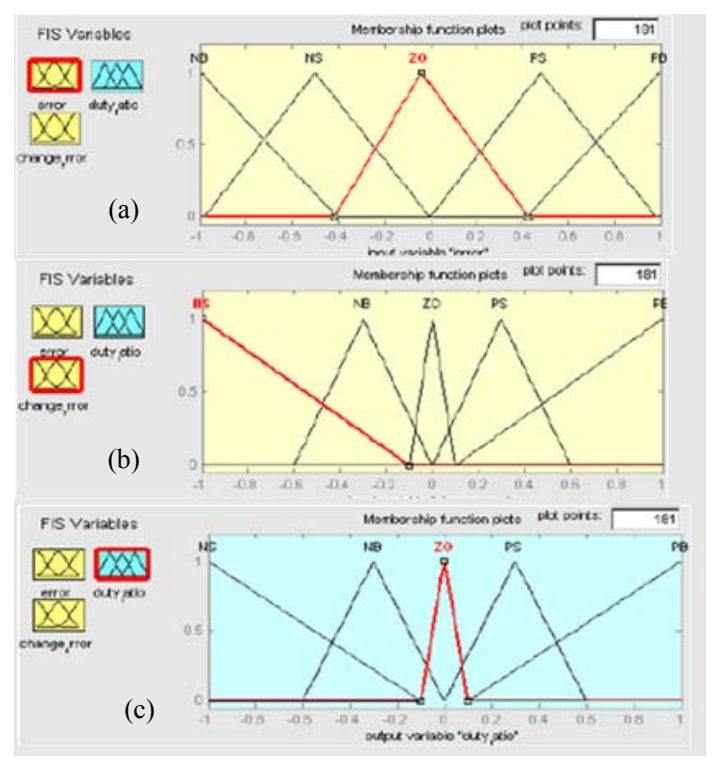

Fig. 8. Member ship functions of e,de and duty ratio

TABLE I. FUZZY TABLE

\begin{tabular}{|c|c|c|c|c|c|c|}
\hline \multicolumn{2}{|c|}{ Duty ratio } & \multicolumn{5}{|c|}{ error } \\
\cline { 3 - 7 } \multicolumn{2}{|c|}{} & NB & NS & ZO & PS & PB \\
\hline de & NB & NB & NB & NB & NS & ZO \\
\cline { 2 - 6 } & NS & NB & NB & NS & ZO & PS \\
\cline { 2 - 6 } & ZO & NB & NS & ZO & PS & PB \\
\cline { 2 - 7 } & PS & NS & ZO & PS & PB & PB \\
\cline { 2 - 7 } & PB & ZO & PS & PB & PB & PB \\
\cline { 2 - 7 } & NB & NB & NS & ZO & PS & PB \\
\hline
\end{tabular}


The simulation result of the proposed method compared to the conventional PSF method with PI controllers is shown in Figure 9. To have a better comparison of system output for both traditional PSF methods and using intelligent algorithms (fuzzy), the system output is represented herein for both types of controllers. Both control systems are simulated under the same conditions for 0.5 seconds. It should be noted that in both systems, wind is applied to all turbines at nominal rate. Because, under the same conditions, three outputs will be identical in both systems, only the output of the first turbo generators of both systems will be shown and compared. First, we show the DC power output of the wind system with traditional PSF controller (with PI) and fuzzy controller will be presented after simulation with software Figure 9. Simulation results show that the output power amplitude is much better than using the PI controller. In the next step, variable and different wind velocities are applied to each turbine and the results of the proposed control system is illustrated Figure10.

(a)

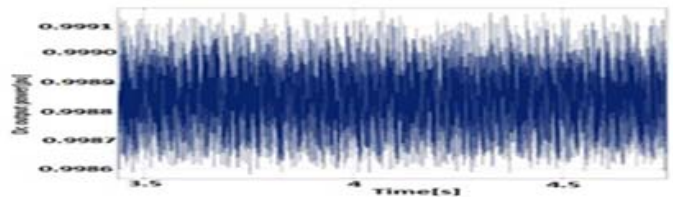

(b)

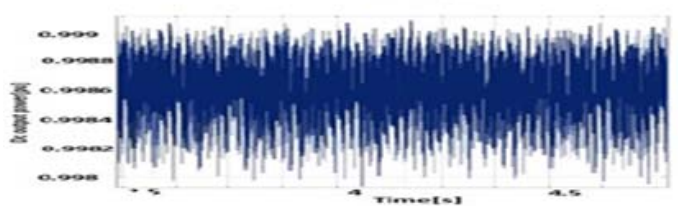

Fig. 9. Output power of 1 th genrator in $0.5 \mathrm{~S}$ (a) with the proposed controller (b) with a PI controller

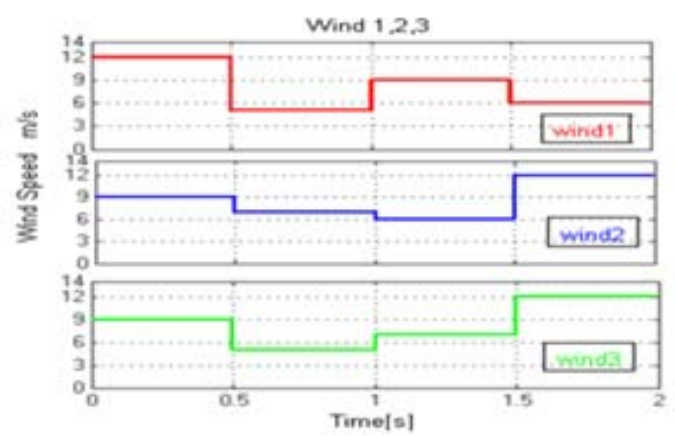

Fig. 10. Three diffirent wind speeds

As it is obvious from the figures, the output power of each wind turbine is subject to wind changes (Figure 11). Figure 12 shows the output power of total turbines, which is applied to the electrolyzer system. As it can be observed, this amount is approximately equal to the sum of three turbines, which is indicative of the validity of the proposed control system. Figure 13 shows the AC [line-line] voltage of each of the generators. As it was mentioned in the introduction section, variable wind velocities in these turbines produce a voltage with variable range and frequency.

\section{CONCLUSION}

In this study, an isolated wind system was proposed to produce hydrogen in remote areas. It uses a combination of three sets of turbo-compressors with fuzzy controllers. The power of the total production can be applied to a set of hydrogen electrolyzers to produce hydrogen. The advantage of this system is the parallel use of multiple turbines which increases the reliability of the system. This process is implemented using a fuzzy control algorithm and for every change of wind speed it was shown that the control system could satisfactorily meet the set objectives. As the rapid changes of the wind speed are carefully followed and responded in an appropriate manner and the maximum power is injected to load. Compared to systems with traditional PSF controller, the proposed system has a better performance in terms of range of fluctuations. On the other hand, since the fuzzy system is independent of the system internal specifications, this can also be regarded as one of the advantages of the proposed system.
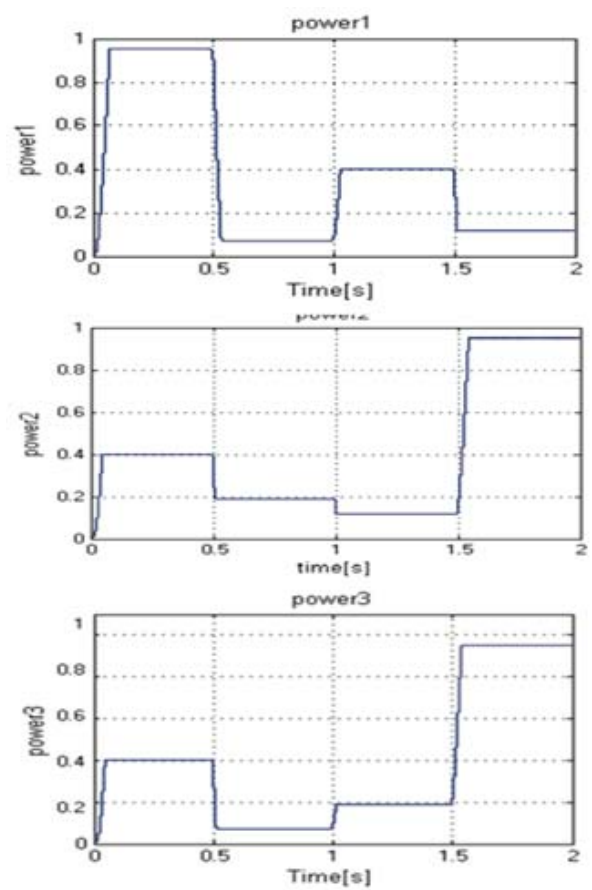

Fig. 11. Output power for each generator

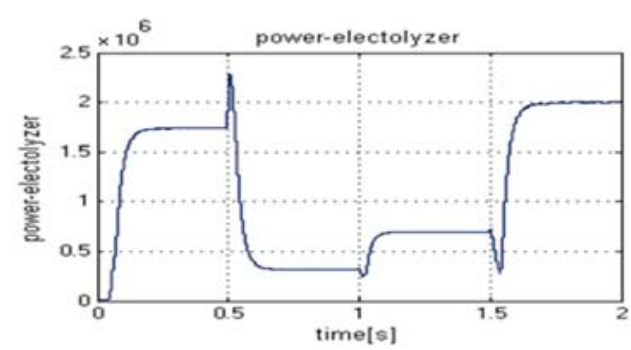

Fig. 12. Total output delivered to the electrolyzer 


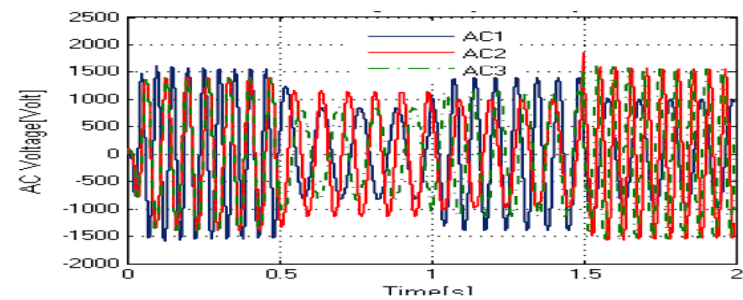

Fig. 13. Output voltage of three PMSG[L-L]

TABLE II. PARAMETERS OF THE TURBINE-GENERATOR SYSTEM

\begin{tabular}{|c|c|}
\hline \multicolumn{2}{|c|}{ PMSG (salient-pole) } \\
\hline Rated Output & $1[\mathrm{MVA}]$ \\
\hline Rated Voltage & $1025[\mathrm{~V}]$ \\
\hline d axis reactance & $7[\mathrm{mH}]$ \\
\hline q axis reactance & $5.5[\mathrm{mH}]$ \\
\hline Winding resistance & $0.01[\Omega]$ \\
\hline Back EMF waveform & Sinusoidal \\
\hline Pole pairs & 51 \\
\hline Frequency & $20[\mathrm{~Hz}]$ \\
\hline Flux linkage established by magnets & $9.76[\mathrm{~Wb}]$ \\
\hline Wind turbine & $2[\mathrm{MW}]$ \\
\hline Rated power Pwn & $23.33[\mathrm{rpm}]$ \\
\hline Rated Rotational Speed & $12.205[\mathrm{~m} / \mathrm{s}]$ \\
\hline Rated Wind Speed & $36[\mathrm{~m}]$ \\
\hline Radius of Wind Turbine & 0.441 \\
\hline Maximum Power Coefficient $c_{\mathrm{p}}$ & \\
\hline \multicolumn{2}{|c}{}
\end{tabular}

\section{ACKNOWLEDGMENT}

The authors are grateful to the National Iranian Gas Transmission Company-8th District of Gas Transmission Operation (NIGTC-DIST8) for the support.

\section{REFERENCES}

[1] L. Barote, C. Marinescu, M. N. Cirstea. "Control structure for singlephase stand-alone wind-based energy sources", IEEE Transactions on Industrial Electronics, Vol. 60, No. 2, pp. 764-72, 2013

[2] H. Zhao, Q. Wu, C. N. Rasmussen, M. Blanke, "L1 Adaptive Speed Control of a Small Wind Energy Conversion System for Maximum Power Point Tracking", IEEE Trans. Energy Convers., Vol. 29, No. 3, pp. 576-584, 2014
[3] H. Kaneuchi, T. Yachi, T. Tani, "Effect of an EDLC in a wind turbine system for hydrogen production", 29th IEEE International Conference on Telecommunications Energy (INTELEC), Rome, October, 2007

[4] K. Koiwa, R. Takahashi, J. Tamura, "A study of hydrogen production in stand-alone wind farm", 2012 International Conference on Renewable Energy Research and Applications (ICRERA), November 11-14, 2012

[5] R. J. Mantz, H. De Battista, "Hydrogen production from idle generation capacity of wind turbines", International Journal of Hydrogen Energy, Vol. 33, No. 16, pp. 4291-300, 2008

[6] A. Gargoom, A. M. Osman Haruni, M. E. Haque, M. Negnevitsky, "Hybrid stand-alone power systems with hydrogen energy storage for isolated communities", Transmission and Distribution Conference and Exposition, April 19-22, 2010

[7] S. M. Muyeen, R. Takahashi, J. Tamura, "Electrolyzer switching strategy for hydrogen generation from variable speed wind generator", Electric Power Systems Research, Vol. 81, No. 2, pp. 1171-1179, 2011

[8] I. Gadoura, T. Suntio, K. Zenger, "Improved Dynamic Performance of Multiloop Operation of Paralleled DC/DC Converters Using FuzzyLogic Control", 2002 Nordic Workshop on Power and Industrial Electronics, Stockholm, Sweden, 2002

[9] E. Pican, E. Omerdic, D. Toal, M. Leahy, "Analysis of parallel connected synchronous generators in a novel offshore wind farm model", Energy, Vol. 36, No. 11, pp. 6387-6397, 2011

[10] A. K. Yadav, V. Mehra, A. Ray, A. Markana, M. Lokhande, "Paralleled DC Boost Converters with Feedback Control using PSO Optimization Technique for Photovoltaic Module Application", International Journal of Computer Applications, Vol. 84, No. 16, pp. 20-25, 2013

[11] A. Natsheh, "Chaotic behaviour in parallel-connected DC-DC buckboost converters", Ninth International Conference on Ecological Vehicles and Renewable Energies (EVER), Monte-Carlo, March, 2014

[12] Y. Geng, G. Hua, W. Huangang, G. Pengyi, "A novel control strategy of induction motors for optimization of both efficiency and torque response", 30th Annual Conference of IEEE Ind. Elect. Society, November 2-6, 2004

[13] H. Q. Minh, N. Frederic, N. Essounbouli, H. Abdelaziz, "A new MPPT method for stand-alone wind energy conversion system", 2012 2nd International Symposium on Environment Friendly Energies and Applications (EFEA), June 25-27, 2012

[14] K. L. Lo, L. Khan, "Fuzzy logic based SVC for power system transient stability enhancement", International Conference on Electric Utility Deregulation and Restructuring and Power Technologies, DRPT 2000, April 4-7, 2000

[15] S. Muyeen, J. Tamura, T. Murata, Stability augmentation of a gridconnected wind farm, Berlin: Springer, 2009 